\title{
Travestilidades versus agentes de segurança pública: A produção acadêmica brasileira com base em um levantamento bibliométrico
}

\section{Cassiano Ricardo Martines Bovo}

Fundo Mackenzie de Pesquisa, São Paulo, SP, Brasil

\begin{abstract}
Este artigo é fruto de um levantamento bibliométrico com o objetivo de registrar obras que abordam as relações entre travestis e agentes de segurança pública de maneira central, na forma de livros, capítulos de livros, teses, dissertações e artigos publicados em periódicos e anais de eventos. Os resultados dessa produção foram apresentados por meio de tabelas e quadros, ressaltando-se, e cruzando-se, autores, quantidades, evolução temporal e temas, com as devidas interpretações.
\end{abstract}

Palavras-chave: bibliometria, travestis, travestilidades, policiais, agentes de segurança pública
Transvestilities versus Public Security Agents: The Brazilian Academic Production Based on Bibliometric Survey is the result of a bibliometric survey with the objective of register works with approach of relations between transvestites and public security agents centrally, in the form of books, book chapters, doctoral theses, master's dissertation and articles published in periodicals and annals of events. The results of this production were presented through tables and frames, highlighting, and crossing, authors, quantities, temporal evolution and themes, with the proper interpretations.

Keywords: bibliometry, transvestites, transvestilities, police officers, public security agents

\begin{abstract}
"É necessário que o mestre entenda que nós estamos lidando com os restos da sociedade" foi uma frase proferida durante uma exposição feita por um aluno sobre o seu ofício de policial (...). Que representações estes policiais têm deles próprios que os diferenciam dos outros, dos diferentes, dos indivíduos que compõem os restos? (SILVA, 2006a, p. 106).
\end{abstract}

\section{Considerações iniciais}

$\mathbf{E}$ ste artigo é fruto de aproximadamente dois anos de escavações em busca de obras que abordam, de maneira central, as relações entre travestis e questões de segurança pública, sobretudo as ações que partem de seus agentes (policiais civis e militares, guardas municipais, delegados, investigadores, agentes penitenciários e autoridades da área).

A produção acadêmica sobre travestis, travestilidade, transexualidade, transgeneridade etc. cresce consideravelmente, em especial a partir da década de 1990, envolvendo as ciências sociais, saúde e humanidades, e coincide com a expansão de grupos e núcleos de pesquisa, assim como de movimentos e organizações LGBT+ e políticas públicas. Toda essa profusão vem na esteira dos debates em torno das questões de gênero, primordialmente da teoria queere das discussões sobre interseccionalidade, levadas 
a cabo por autoras como Judith Butler, Joan Scott, Gayle Rubin, entre outras. No Brasil, despontam pensadores como Berenice Bento, Larissa Pelúcio, Richard Miskolci, Guacira Lopes Louro etc.

Os assuntos dessa produção envolvem as mais variadas facetas do difícil cotidiano das travestis, desde sua infância, passando por questões filosóficas, educação, saúde, violação de direitos, movimentos, prostituição, envelhecimento, dentre outros, na forma de etnografias, historiografias, ensaios, entrevistas, autobiografias, biografias, romances, interpretações analíticas etc. Via de regra, a violência, nas suas mais variadas formas, assim como violações de direitos, são presença constante nessas obras, vindo das mais variadas direções e atores sociais, inclusive daqueles que em tese menos se esperaria: agentes de segurança pública.

Assim, no significativo volume de obras acerca da travestilidade, selecionei aquelas centralmente relacionadas com as ações de agentes de segurança pública em direção às travestis, em um período que abarca o regime militar brasileiro até 2016, nos mais variados ambientes (ruas e avenidas, camburões, delegacias, prisões e demais instituições de segurança pública), contemplando também processos de investigação e políticas públicas relacionadas à segurança pública.

Apresento o resultado do levantamento por meio de informações e dados estatísticos, como é de praxe no âmbito da bibliometria ${ }^{1}$. O caminho escolhido, dentre as muitas possibilidades, está explicitado na seção "Procedimentos metodológicos" deste texto e prioriza a evolução cronológica, os tipos de obras e a divisão por temas da produção em pauta.

Cabe esclarecer o que entendo por travestilidade neste artigo, o que equivale a perguntar: quem são as pessoas - que não os agentes de segurança pública — consideradas no levantamento realizado? Ao responder, é necessário encarar a armadilha linguística de nomear com uma palavra um conjunto diverso de configurações existentes, o que é sempre simplificador e, portanto, exige algumas considerações.

Minha referência são as pessoas que nasceram em um corpo biologicamente masculino e realizam, ao longo da vida, transformações corporais em direção ao feminino, assim como vivenciam comportamentos e performances associadas às mulheres. As mudanças no corpo, ao longo da vida e variando muito entre elas, envolvem a utilização de hormônios, aplicações de silicone, procedimentos estéticos desde os mais simples até os cirúrgicos, principalmente a colocação de próteses (seios), chegando, em alguns casos, à operação chamada de redesignação sexual ou transgenitalização, no caso a substituição do pênis pela vagina. As identificações de gênero impostas a esse grupo de pessoas são diversas e cercadas de classificações médicas e psiquiátricas, legais, culturais e políticas, imersas em processos de controles sobre mentes e corpos.

Os diagnósticos do saber médico as classificou de travestis e transexuais (femininas), rotulando-as com subdivisões - travesti fetichista, transexual verdadeira etc. Porém, os movimentos e as políticas públicas, embora mantendo certa rigidez, descolaram-se dessas nomenclaturas em função dos seus diferentes objetivos, e quando se trata da - que mais importa 
— autoidentificação, abre-se rico leque de possibilidades identitárias, marcado pela diversidade, fluidez e mutabilidade $^{2}$, na intersecção com questões culturais, de classe social, diferenças geracionais, estereótipos associados à prostituição, vivência subjetiva em relação ao pênis, influência regional e religiosa, saber médico, movimentos e políticas públicas, entre outros. Como afirma Leite Jr. (2008, p. 195), “o interessante é observar o descompasso entre as rígidas classificações oficiais e a fluidez das identificações cotidianas que estão constantemente se interpenetrando".

Aliás, está cada vez mais em jogo a própria noção de identidade de gênero. A seguinte afirmação de Judith Butler (2003), justamente a respeito das travestis, aponta para esse aspecto:

Eu sugeriria, igualmente, que o travesti subverte inteiramente a distinção entre os espaços psíquicos interno e externo, e zomba efetivamente do modelo expressivo do gênero e da ideia de uma verdadeira identidade do gênero (BUTLER, 2003, p. 236) ${ }^{3}$.

Optei pela utilização da combinação travesti/lidade para expressar essa miríade de possibilidades por dois motivos. Em primeiro lugar, em decorrência do histórico enraizamento dos termos na sociedade brasileira. Em segundo, pelo fato de a maioria das obras levantadas os utilizarem. A Tabela 1 abaixo dá uma ideia, ainda que superficial, de sua utilização nos títulos das obras coletadas ${ }^{4}$.

Tabela 1: Frequência dos conjuntos de palavras nos títulos das obras coletadas

\begin{tabular}{|l|c|c|}
\hline \multicolumn{1}{|c|}{ Palavras } & Registros & Porcentagem (\%) \\
\hline Travesti/s/lidade & 54 & 46,15 \\
\hline Transexual/is/lidade & 16 & 13,68 \\
\hline LGBT & 16 & 13,68 \\
\hline Homo/trans/fobia & 14 & 11,97 \\
\hline Homossexuais/lidade & 11 & 9,40 \\
\hline Transgênero/s & 6 & 5,13 \\
\hline Total & 117 & 100 \\
\hline
\end{tabular}

Fonte: Elaboração do autor.

Evidencia-se, portanto, que não considerei homens transexuais (homens trans ou transexuais masculinos) no levantamento, o que aumentaria sensivelmente o esforço da empreitada, embora em algumas obras eles estejam presentes, assim como gays e lésbicas, geralmente sob o manto LGBT+, em função de semelhanças de vivências.

Assim, o caminho a ser percorrido neste artigo, além dessas considerações iniciais, é o seguinte: realizo uma descrição panorâmica das relações entre travestis e agentes de segurança pública ao longo do tempo; em seguida, explico os procedimentos metodológicos adotados; depois, apresento os resultados do levantamento bibliométrico envolvendo toda a produção; na última seção, exponho os resultados divididos por temas. Finalmente, teço as considerações finais. 


\section{Breve panorama das relações entre travestis e agentes de segurança pública ao longo do tempo}

O momento da opção, de forma praticamente generalizada, da prática da prostituição como sobrevivência, por parte das travestis brasileiras, coincide justamente com um período em que as polícias civil e militar realizavam o seu esquadrinhamento da cidade de forma cada vez mais truculenta ${ }^{5}$, sob a égide da Doutrina de Segurança Nacional. Sobretudo nas décadas de 1970 e 1980, a caça a prostitutas, michês e principalmente travestis se consubstancia em megaoperações chamadas de “operações limpeza", arrastões, "rondões", além de blitzes. Em São Paulo, por exemplo, isso aconteceu de forma expressiva sob a alçada do Cel. Erasmo Dias, secretário de Segurança do Estado de São Paulo, no período de 1974 a 1979; o comando do delegado Sergio Richetti, da Delegacia Seccional Centro, a partir de maio de 1980; e o saber - das pesquisas com ares de cientificidade - do delegado Guido Fonseca, com o apoio e estímulo do jornal O Estado de S. Paulo 6 , na forma de cruzada moralista, pretensamente em nome dos anseios das famílias paulistanas e dos chamados "homens de bem".

Como decorrência, muitas travestis eram encarceradas e enquadradas sob a alegação de vadiagem e atentado ao pudor, muitas vezes ilegalmente. Opressão, violência, violação de direitos se davam nas ruas, camburões, delegacias e prisões, na forma de humilhação, descaso, tortura, espancamento, estrupo, achaque, homicídio etc. Se iniciava algo que nunca se desfez, com um vigor que se manteve ao longo do tempo, com diferentes modulações, gradações, abrangência, frequência, níveis de violência e formas de discursividade, além de suas variações locais.

As travestis são nacionalmente associadas à prostituição. Embora se careça de dados confiáveis, inclusive em relação à participação das que se prostituem dentre o total, a relação ficou evidenciada a partir de meados dos anos 1970. Na ocasião, sistemas específicos de repressão às travestis que se prostituíam foram criados. Da década de 1940 até esse período divisor de águas, a visibilidade dessas se dava no carnaval, em bailes e concursos de fantasia e, em especial nos anos 1960, em espetáculos musicais e teatrais. A vivência prostitucional, de forma maciça, tem forte relação com a disseminação do silicone industrial e das próteses (seios) como estratégia de modelagem corporal. Interessante que esse processo se deu em pleno período de repressão política e policial, que também atingia as homossexualidades e atividades de prostituição, na conexão com o conservadorismo dos costumes.

Simultaneamente, emergiram ricos processos criativos de contestação, movimentos e afloramento de desejos. As travestis fazem parte dessa história. Ao mesmo tempo que puderam criar corpos esculturais, aumentava consideravelmente a demanda constituída de homens dispostos a pagar por programas ${ }^{7}$. Ademais, as travestis, dadas suas dificuldades (rejeição familiar, escolar, preconceito, discriminação, violências etc.), percebem a prostituição como solução econômica para realizarem as contínuas transformações corporais exigidas pelo próprio mercado, 
presas em uma engrenagem de exploração (cafetinagem) de que muitas não conseguem mais se desvencilhar. Ressalto que a maior parte das obras coletadas envolvem interações que têm como pano de fundo as atividades da prostituição.

$\mathrm{Na}$ associação da psiquiatria com a criminalística, alimentada pelo julgamento moral que associa travestilidade com perversão, aflora um estigma criminoso associado às travestis. Nisso tudo está a se punir o modo travesti de ser. Chama atenção, nesse período, a estratégia de podersaber encaminhada pelo então delegado Guido Fonseca, que implantou a política de registrar e arquivar os dados das travestis da cidade de São Paulo, com ênfase para fotos e desenhos com os traços característicos de cada uma, seguindo o rastro da criminalística de Cesare Lombroso.

O processo de redemocratização da sociedade brasileira, a partir de 1985, nada alterou em relação às violências e violações de direitos sofridas pelas travestis, a exemplo da atuação policial em geral, em que pese à diminuição da frequência da ocorrência das megaoperações ${ }^{8}$. Relatos, denúncias, matérias jornalísticas, etnografias para as principais cidades do país ao longo das décadas de 1980 e 1990 dão conta de um poder praticamente ilimitado para policiais praticarem as mais variadas barbaridades de forma impune e sem qualquer preocupação com as consequências de suas ações, ao largo da lei, inclusive, em muitos casos, beneficiando-se sexual e monetariamente em ações relacionadas às travestis.

Embora situações desse tipo continuem a acontecer até os dias de hoje, a bibliografia, assim como relatos e matérias de mídia, existente a respeito assevera que a partir dos anos 2000 começa a ocorrer um abrandamento, embora variando muito de intensidade, localidade e formas de atuação e controle exercido por agentes de segurança pública:

Num determinado momento, depois da luta organizada dos movimentos sociais de travestis e transexuais, aquela violência que a polícia jogava a qualquer momento no camburão, levava para delegacia e deixava mofando por horas, tinha diminuído muito (LUCON, 12/02/2016).

Os relatos a respeito das ações de policiais, em relação às travestis, ao longo do tempo e variando de local a local, costumam mencionar: xingamentos, humilhações, omissão, ameaças, espancamentos, tortura, propina (dinheiro ou sexo), detenções arbitrárias, chegando-se, em alguns casos, ao extremo do homicídio. Por outro lado, há, também, cooperação, solidariedade, benefícios mútuos e oportunistas - que não deixam de se constituir em uma forma de controle —, afetividade, desejo e respeito aos direitos. Muitas vezes as relações se tornam amistosas, de colaboração e proteção:

De um lado, ela é prestativa, parceira (...). De outro, os policiais se apropriam de seu lugar legitimado pelos aparatos estatais para cometer abusos e ofensas morais. As experiências de contato com a polícia, portanto, são bastante diferentes entre elas (CARDOZO, 2009, p. 152). 
Garcia (2007), por exemplo, menciona a existência de condutas bastante antagônicas ao criar uma tipologia de policiais.

A invisibilização das travestis, bem como a banalização da violência e os assassinatos decorrentes, ocorrem paralelamente em outra instância relacionada à segurança pública: os processos de investigação. Carrara e Vianna (2006), em pesquisa realizada para o caso específico do munícipio do Rio de Janeiro, concluem algo que é recorrente para o país até os dias de hoje: a maioria das mortes de travestis tem investigação inconclusa, arquivamento precoce, sem solução, ausentes procedimentos básicos de investigação, às vezes sem sequer descobrir quem era a vítima. Além disso, boa parte dos processos e inquéritos é carregada de estereótipos e desqualificações. O resultado da maioria dos processos em que se chega ao final é a absolvição - quer dizer, a impunidade.

Pelo lado da mídia (jornais, programas de rádio e TV), costuma-se dar bastante destaque para ações e discursos de agentes de segurança pública envolvidos em ações e investigações relacionadas às travestis. Estereótipos e preconceitos são frequentes nessas coberturas, de acordo com o que pensa parcela significativa da sociedade, que recrimina opções identitárias fora da moldura heteronormativa ${ }^{9}$. O fato é que policiais, em especial delegados, gozam de enorme poder nas veiculações da mídia. Essas questões são abordadas por parcela das obras deste levantamento. Por exemplo, a maioria dos capítulos de Diniz e Oliveira (2014) que, ao analisar a metodologia das matérias jornalísticas, apontam como os interesses das forças de segurança se relacionam com os meios de comunicação.

Parcela significativa das travestis já vivenciou o encarceramento e essa é questão extremamente importante nas relações entre travestis e agentes de segurança pública, uma vez que o que ocorre fora das grades é reproduzido de forma mais intensa atrás delas. Quantidade bastante significativa de obras deste levantamento vai se debruçar sobre o assunto ${ }^{10}$. Estudiosos e organizações LGBT+ costumam apontar para uma questão muito evidente: o sistema prisional não foi pensado para as pessoas trans. Nem sempre $\mathrm{o}$ aprisionamento das travestis em alas femininas é garantia de menos violência, podendo ocorrer $\mathrm{o}$ contrário. Aliás, a demanda dos movimentos é a de que elas tenham o direito de decidir a esse respeito.

Há poucos exemplos de presídios que possuem alas ou galerias LGBT+, onde as travestis pretensamente podem se sentir mais seguras, protegidas, o que muitas vezes não acontece e, em geral, não evita violações de direitos. "Porém, segundo os pesquisadores, a separação dos demais presos não faz com que os detentos estejam isentos de castigos e abusos por parte, inclusive, dos servidores" (ROLIM, 2018). Além disso, mesmo havendo a proteção, em geral, o resultado é um nível de estigmatização no ambiente prisional que leva à restrição de acesso a direitos que a maioria dos demais presos tem, tais como trabalho e educação. Se a segregação e a seletividade penal são marcas registradas em relação às travestis fora das grades, no ambiente prisional se trata de uma hiper-segregação (PRADELLA e FRANÇA, 2015 apud SÁ, 2015). 
No que diz respeito às políticas públicas relacionadas às travestilidades, na década de 1980 emergiu a questão da saúde, sobretudo em função do HIV, uma vez que as travestis foram rotuladas como grupo de risco, com repercussões estigmatizantes. A segurança pública teve que esperar um bom tempo para entrar no radar das preocupações em termos de políticas.

\begin{abstract}
Como se não pertencesse à mesma cidade ou ao mesmo país, o panorama na segurança pública distinguia-se fortemente do cenário da saúde. Do lado desta, autoridades e funcionários de secretarias e programas do ministério, ainda que nos primeiros anos da democratização, isto é, na primeira metade da década de 1980, pareciam considerar rotineiro receber, dialogar — e frequentemente confrontar-se com atores sociais tão distintos como lideranças homossexuais, feministas, hemofílicos, empresários, dirigentes de organizações não-governamentais e jornalistas. Do lado da segurança, mesmo que já estivéssemos no último ano da década de 1990, encontravam-se gestores e policiais sem qualquer experiência ou memória de diálogo com movimentos sociais organizados. Os ativistas, por sua vez, não tinham uma agenda clara de reivindicações para a segurança pública (RAMOS, 2010, p. 128).
\end{abstract}

Em termos de políticas públicas, apesar das experiências anteriores, a temática LGBT+ só deixou de ser um "estado de coisas" para se tornar um "problema político" (SOUZA, 2015) a partir do Programa Brasil sem Homofobia, do Governo Federal (CNDC, 2004), que desencadeou uma série de iniciativas nas décadas de 2000 e 2010, tais como: elaboração de planos, programas, relatórios, criação de secretarias especializadas, comitês, conselhos - inclusive de segurança pública —, sistemas, órgãos de denúncia, realização de eventos (conferências e seminários), surgimento de datas, na conexão com iniciativas não só especificas à questão LGBT+, como os Programas Nacionais de Direitos Humanos (1996, 2002, 2009) e a Conferência Nacional de Segurança Pública (2009). Especificamente relacionando segurança pública e LGBT+, solitariamente, tivemos o Plano Nacional de Segurança Pública para o Enfrentamento da Homofobia, de 2007 (SILVA, 2007). "Apesar do ineditismo e da densidade das propostas, o referido Plano Nacional de Segurança Pública para o Enfrentamento da Homofobia até o momento não foi institucionalizado pelo Governo Federal" (MELLO, AVELAR e BRITO, 2014, p. 11).

Embora não seja aqui o espaço adequado para aprofundar as questões e controvérsias sobre as políticas públicas, entre a profusão de iniciativas e o que de fato se apresenta Mello, Brito e Maroja (2012) afirmam:

\footnotetext{
No que diz respeito à implementação de políticas públicas para a população LGBT no Brasil, a despeito dos avanços recentes nas iniciativas governamentais, o que se observa é que nunca se teve tanto e o que há é praticamente nada (Ibid., p. 11).
}

Uma das maiores dificuldades apontadas é transformar as tantas iniciativas em algo permanente, inclusive na forma de leis e processos concretos, de modo a não depender de governantes de plantão para sua aplicação. As maiorias legislativas que imperam no país, geralmente ancoradas em influências 
conservadoras, têm restringido esses processos; os avanços têm se dado no âmbito dos poderes Executivo (federal, estaduais e municipais) e Judiciário, sobretudo o Superior Tribunal Federal.

Nesse rol de iniciativas raramente há algo específico sobre as travestilidades, que costumam ser englobadas de forma genérica no grupo LGBT+, a partir de problemáticas em comum. Já a questão da segurança pública conta com seções, itens e pontos que vieram aumentando ao longo do tempo, mas o mote costuma ser as violências, a discriminação e o preconceito inscritos de forma generalizada na sociedade e são poucos os trechos referentes à atuação de agentes de segurança pública em relação às travestis. Os conteúdos, nesse sentido, se referem ao atendimento nas delegacias, ao registro das ocorrências, coleta de informações e criação de sistemas padronizados para geração de dados e estatísticas - sobretudo para a comprovação de crimes com motivação homo/transfóbica, assim como para a penalização —, treinamento e capacitação de policiais, normas e procedimentos para atuação dos agentes, processos investigatórios e tráfico de pessoas. Há também partes relacionadas às travestis no sistema prisional.

De qualquer forma, em relação ao universo trans, assistimos, mais recentemente, a algumas conquistas, tais como: obrigatoriedade do respeito ao nome social nas instituições em geral, assim como a emissão de documentos de identificação, legalização da união homoafetiva e dos procedimentos de adoção, flexibilização das exigências para realização da operação de redesignação sexual, estímulo ao acesso às políticas de saúde e a equiparação da homo/transfobia ao crime de racismo. Embora não se trate diretamente de questões relacionadas à segurança pública, os seus agentes, nas ações, legalmente são obrigados a respeitar, em que pese às resistências, uma vez imersos na moldura cultural heteronormativa que permeia a sociedade brasileira, reforçada pelo crescimento avassalador de grupos conservadores quanto à questão de gênero e sexual. Isso, por si só, deveria estimular experiências de capacitação e conscientização com esses agentes, o que é dificultado pela cultura que impera nas instituições de segurança pública, que preza pela masculinidade, rígida hierarquia, militarização e lógica do ataque ao inimigo, além da comprovada impunidade para com violações de direitos humanos cometidas por policiais. São fatores reforçadores de preconceitos e estigmas.

No final das contas, no que diz respeito a agentes de segurança pública na sua relação com as travestis, dependemos muito de iniciativas, geralmente isoladas, de governos estaduais e prefeituras. Com relação às experiências de capacitação, reciclagem, treinamento e aperfeiçoamento no sistema de denúncias, destaco três: Governo do Estado do Rio de Janeiro (RAMOS, 2001, 2010; MARTINS, 2001) e do Rio Grande do Sul (SILVA, 2006a, 2006b), ambas no final dos anos 1990 e início da década seguinte, e Guarda Municipal de Fortaleza, entre 2005 e 2012 (NATIVIDADE, 2013). Cumpre destacar que em todas, de alguma forma, houve participação de travestis, expondo o universo das travestilidades, situações, problemas etc. em reuniões, palestras e até na docência, o que as cercou de conflitos, resistências e controvérsias. 
Conquanto nos três casos relatados chame atenção a falta de continuidade, sobretudo pela mudança de governos, o fato é que, apesar das dificuldades, limitações e resistências, bem ou mal foi se inserindo, ao longo do tempo, matérias ou abordagens relativas às questões de gênero e às travestilidades. A inserção deu-se em graus muito diferentes de profundidade, abrangência e ênfase nas aulas, palestras, workshops dos cursos de formação, capacitação e reciclagem nas instituições de segurança pública - em especial polícias civil e militar e guardas municipais -, conforme se observa atualmente em boa parte do país. Entretanto, ainda carece de resultados mais concretos nas ruas, delegacias e unidades prisionais.

\section{Procedimentos de pesquisa}

Minha fonte de pesquisa para o levantamento bibliométrico foi a Plataforma Lattes do Conselho Nacional de Desenvolvimento Científico e Tecnológico (CNPq), utilizando os termos de busca "travesti", "travestis", "travestilidade", "transexualidade" e "transexuais". O fato é que a grande maioria dos autores e pesquisadores lança - até por exigência institucional, em muitos casos - sua produção, de todos os tipos, nesse canal, tornando-se recorrente padrão de conduta. Entendo que esse caminho cobre parcela bastante considerável da bibliografia existente sobre o assunto. Como forma de cobrir lacunas, a busca foi reforçada pelo procedimento de verificar as referências bibliográficas de todas as obras a que tive acesso, enquadrando-se ou não neste levantamento. As dificuldades em se chegar a 100\% de toda a produção almejada parecem-me evidentes; porém, acredito ter estado próximo a esse patamar, desde que se considerem os critérios de seleção a seguir explicitados.

Tudo que descobri nessa busca inicial foi acessado e manuseado visando à verificação de dois requisitos cruciais para o enquadramento, ou não: a abrangência e a importância do tema relações entre travestis e agentes de segurança pública no conteúdo de cada obra. Em outras palavras, o quanto que o assunto está presente na obra: apenas em uma seção? Em um capítulo ${ }^{11} \mathrm{E}$, fundamentalmente, a centralidade, isto é, se há o objetivo de abordar o tema ${ }^{12}$. As ações de agentes de segurança pública povoam o cotidiano das travestis, o que explica menções ao assunto em muitas obras, mas ser este o objeto de investigação/preocupação é outra questão.

Cumpre registrar o árduo trabalho de seleção na medida em que tive que acessar as mais variadas obras sobre a travestilidade, uma vez que, nesse caso, não se pode fiar nos seus títulos.

Foram coletados os seguintes tipos de obras: livros, capítulos de livros ${ }^{13}$, artigos em periódicos, artigos completos publicados em anais de eventos (congressos, seminários, simpósios, conferências, encontros, internacionais, nacionais ou locais), dissertações de mestrado e teses de doutorado. Desconsiderei 
relatórios, dossiês, trabalhos de conclusão de curso de graduação e pós-graduação lato sensu, resenhas, resumos de eventos científicos, textos publicados em boletins, blogs, sites ou publicações do tipo.

Produções contendo o mesmo título, porém de tipos diferentes foram todas consideradas ${ }^{14}$. A razão desse procedimento está no fato de que, embora se trate de uma repetição, a computação de todos os tipos revela o nível de produção e inserção do assunto no meio acadêmico.

\section{Apresentação e interpretação dos resultados}

O objetivo desta seção é a apresentação da produção total do levantamento bibliométrico em uma perspectiva quantitativa, relacionando evolução temporal, tipos de obras, instituições, áreas e periódicos.

A Tabela 2 abaixo oferece uma ideia do quadro geral de toda produção coletada ao longo do tempo, por meio de um cruzamento de possibilidades ${ }^{15}$.

Tabela 2: Produção total e relativa em todo o período

\begin{tabular}{|c|c|c|c|c|c|c|c|c|}
\hline Ano & Livros & $\begin{array}{l}\text { Capítulos } \\
\text { de livro }\end{array}$ & $\begin{array}{c}\text { Artigos } \\
\text { periódicos }\end{array}$ & $\begin{array}{c}\text { Artigos } \\
\text { anais }\end{array}$ & Teses & Dissertações & Total & $\%$ \\
\hline 1987 & & 1 & & & & & 1 & 0,91 \\
\hline 1996 & & 1 & & & & 1 & 2 & 1,82 \\
\hline 2001 & 1 & & & & & & 1 & 0,91 \\
\hline 2006 & & & 1 & 1 & 1 & 1 & 4 & 3,64 \\
\hline 2007 & & 1 & & & & & 1 & 0,91 \\
\hline 2008 & & & 2 & 1 & & & 3 & 2,73 \\
\hline 2009 & & & & & & 1 & 1 & 0,91 \\
\hline 2010 & 1 & 3 & & 2 & & & 6 & 5,45 \\
\hline 2011 & & & & 4 & & 1 & 5 & 4,54 \\
\hline 2012 & 1 & 2 & & 5 & & & 8 & 7,27 \\
\hline 2013 & & & 4 & 9 & & & 13 & 11,82 \\
\hline 2014 & & 13 & 7 & 5 & & 5 & 30 & 27,27 \\
\hline 2015 & 1 & 2 & 4 & 5 & 1 & 2 & 15 & 13,64 \\
\hline 2016 & & 5 & 9 & 1 & 1 & 4 & 20 & 18,18 \\
\hline Total & 4 & 28 & 27 & 33 & 3 & 15 & 110 & $100 \%$ \\
\hline$\%$ & 3,64 & 25,45 & 24,54 & 30,00 & 2,73 & 13,64 & $100 \%$ & \\
\hline
\end{tabular}

Fonte: Elaboração do autor.

Pela vertical tem-se uma ideia da evolução ao longo do tempo. Na horizontal observa-se a subdivisão por tipo de obra a cada ano. As últimas e penúltimas linhas e colunas representam totais e participações percentuais, interpenetrando-se.

Da Tabela 2, depreende-se que: a produção apresentou-se intermitente por um longo período, só a partir de 2006 observa-se continuidade anual; houve uma mudança de padrão a partir de 2013, uma vez 
que ocorre um salto no número de obras e depois nunca mais voltou a algo inferior à produção desse ano, porém, não se observa evolução gradativa ao longo do tempo, mas alternâncias abruptas ${ }^{16}$; a produção do período 2013-2016 corresponde a 71\% do total, mais de dois terços, o que revela maior interesse pela temática mais recentemente; no que diz respeito à produção total por tipos de obras, predomina capítulos de livros e artigos publicados em periódicos e anais de eventos, correspondendo a $80 \%$ do total.

A Tabela 3 abaixo apresenta a produção vista pelo ângulo das teses e dissertações apenas.

Tabela 3: Teses e dissertações por Instituições de Ensino Superior (IES)

\begin{tabular}{|c|c|c|c|}
\hline Instituição & Tese de doutorado & Dissertação de mestrado & Total \\
\hline UFSC & 1 & 2 & 3 \\
\hline USP & 0 & 3 & 2 \\
\hline UFRGS & 1 & 1 & 2 \\
\hline PUC-RS & 0 & 2 & 2 \\
\hline PUC-SP & 0 & 2 & 1 \\
\hline Ufam & 1 & 0 & 1 \\
\hline UFPB & 0 & 1 & 1 \\
\hline Unicamp & 0 & 1 & 1 \\
\hline Uerj & 0 & 1 & 1 \\
\hline UFMG & 0 & 1 & 18 \\
\hline UCS ${ }^{17}$ & 0 & 1 & 15 \\
\hline Total & 3 & & 1 \\
\hline
\end{tabular}

Fonte: Elaboração do autor.

Nesse quesito, as duas principais IES são Universidade Federal de Santa Catarina (UFSC) e Universidade de São Paulo (USP). Observa-se a concentração nas regiões Sudeste e Sul. A primeira com oito obras e a segunda com sete, o que representa $83,33 \%$ do total.

Já a Tabela 4 abaixo apresenta essa mesma produção pelo ângulo das respectivas áreas do conhecimento $^{18}$.

Tabela 4: Teses e dissertações por áreas específicas da Capes

\begin{tabular}{|c|c|}
\hline Áreas da Capes & Quantidade \\
\hline Antropologia & 5 \\
\hline História & 3 \\
\hline Direito & 3 \\
\hline Educação & 2 \\
\hline Psicologia & 2 \\
\hline Sociologia & 1 \\
\hline Serviço social & 1 \\
\hline Medicina & 1 \\
\hline Total & 18 \\
\hline
\end{tabular}

Fonte: Elaboração do autor. 
Na Tabela 4, observa-se a predominância da área da antropologia, o que já se esperava, uma vez que a temática é bastante propícia para elaboração de etnografias. O segundo lugar, ocupado pela área da história, revela a preocupação mais recente com a violência policial em tempos mais remotos, principalmente na ditadura militar. Já em relação ao direito, expressa a preocupação com as questões legais no que diz respeito às violações sofridas pelas travestis.

A Tabela 5 abaixo trata da produção referente aos artigos publicados em periódicos, apresentando os mais frequentes.

Tabela 5: Periódicos mais frequentes

\begin{tabular}{|c|c|c|c|}
\hline Nome do periódico & $\begin{array}{c}\text { Quantidade de } \\
\text { artigos publicados }\end{array}$ & Filiação institucional & Curso ou programa \\
\hline $\begin{array}{c}\text { Cadernos de Gênero } \\
\text { e Diversidade }\end{array}$ & 2 & UFBa/Unilab & Grupos de pesquisa \\
\hline $\begin{array}{c}\text { Sistema Penal \& } \\
\text { Violência }\end{array}$ & 2 & PUC-RS & $\begin{array}{c}\text { Programa de Pós- } \\
\text { Graduação em } \\
\text { Ciências Criminais }\end{array}$ \\
\hline
\end{tabular}

Fonte: Elaboração do autor.

Nesse caso observa-se grande fragmentação, uma vez que, de um total de 23 periódicos, envolvendo 27 obras, apenas dois deles (Cadernos de Gênero e Diversidade e Sistema Penal \& Violência) receberam mais de um artigo, revelando a inexistência de um canal específico que se constitua em difusor das questões de travestilidade e agentes de segurança pública.

\section{Temas: travestis e agentes de segurança pública}

Nesta seção procuro apresentar o assunto em pauta dividido em cinco temas ${ }^{19}$ :

- Tema 1: Travestis e agentes de segurança pública no período do regime militar;

- Tema 2: Travestis e agentes de segurança pública no pós-ditadura até os dias de hoje;

- Tema 3: Processos de investigação e apuração de fatos nas instituições de segurança pública;

- Tema 4: Sistema prisional e encarceramento de travestis;

- Tema 5: Políticas de segurança pública relacionadas às travestis.

A Tabela 6 mostra a distribuição percentual referente à produção de cada tema dentro do total ${ }^{20}$. 
Tabela 6: Totais por temas e sua participação na produção total

\begin{tabular}{|c|c|c|c|c|}
\hline Tema 1 & Tema 2 & Tema 3 & Tema 4 & Tema 5 \\
\hline 9 & 20 & 19 & 45 & 17 \\
\hline $8,18 \%$ & $18,18 \%$ & $17,27 \%$ & $40,90 \%$ & $15,45 \%$ \\
\hline
\end{tabular}

Fonte: Elaboração do autor.

Chama a atenção a distância da participação (40,90\%) do Tema 4 (encarceramento de travestis) em relação aos demais que, excetuando-se o Tema 1, ficam muito próximas (entre 15 e 20\%).

Já a Tabela 7 apresenta a evolução temporal de cada tema.

Tabela 7: Evolução da produção ao longo do tempo por temas

\begin{tabular}{|c|c|c|c|c|c|}
\hline Ano & Tema 1 & Tema 2 & Tema 3 & Tema 4 & Tema 5 \\
\hline 1987 & & 1 & & & \\
\hline 1996 & & 2 & & & \\
\hline 2001 & & 1 & & & \\
\hline 2006 & & 1 & 2 & & 2 \\
\hline 2007 & & & & & 1 \\
\hline 2008 & & 1 & & 1 & 1 \\
\hline 2009 & & 1 & & & \\
\hline 2010 & & 1 & 2 & & 3 \\
\hline 2011 & & 2 & 1 & 1 & 1 \\
\hline 2012 & 1 & 1 & 2 & 4 & \\
\hline 2013 & 1 & 1 & 1 & 7 & 3 \\
\hline 2014 & 4 & 1 & 10 & 12 & 3 \\
\hline 2015 & 1 & 4 & & 8 & 1 \\
\hline 2016 & 2 & 3 & 1 & 12 & 2 \\
\hline Total & 9 & 20 & 19 & 45 & 17 \\
\hline
\end{tabular}

Fonte: Elaboração do autor.

Os desdobramentos e as interpretações da Tabela 7 estarão presentes nas próximas subseções, em que serão apresentadas algumas características e dados a respeito da produção de cada tema.

Tema 1: Travestis e agentes de segurança pública no período do regime militar

Trata-se de obras que se concentram na repressão policial - civil e militar, muitas vezes integradas - contra as travestis no período do regime militar (1964-1984), caracterizada pelo alto nível de violência, pela truculência e pela violação de direitos, com apoio da cruzada moral movida por vários setores da sociedade, inclusive parte da mídia, além do aparato jurídico e do saber médico.

O autor que mais produziu sobre esse tema é Rafael Freitas Ocanha: cinco obras para um total de nove nessa produção, o que representa um índice de concentração de $55,55 \%{ }^{21}$. A 
primeira obra - justamente do autor em pauta - é de 2012, diferentemente dos demais temas que têm registros ao menos desde a década de 2000, o que chama atenção, pois só recentemente acontecimentos de um período longínquo vieram a ser objeto de análise. Lembremos que em 2013 assistimos à instituição da Comissão Nacional da Verdade, assim como das comissões estaduais, que, em geral, apresentaram uma seção dedicada à questão LGBT+, alimentando a memória referente a esse período, tanto que o ano de maior concentração nesse tema foi 2014.

$\mathrm{O}$ quadro $^{22}$ abaixo aglutina as palavras em torno do léxico ou da ideia e apresenta sua frequência nos títulos das obras coletadas nesse tema ${ }^{23}$.

Quadro 1: Conjuntos de palavras constantes nos títulos do Tema 1

Combate/repressão/camburão/mira/rondas (7)
Polícia/s/policiais/civil/militar (6)
Imprensa/tinta /jornal/papel (5)
São Paulo (5)

Fonte: Elaboração do autor.

O resultado evidencia a repressão sofrida pelas travestis no período em análise, levada a cabo pelas polícias civil e militar. O terceiro conjunto, relacionado à mídia, reflete as corriqueiras matérias e batalhas a respeito do assunto, veiculadas, especialmente nos jornais $O$ Estado de $S$. Paulo e Folha de S. Paulo, nessa época. Finalmente, a frequência do termo "São Paulo" repercute o fato de boa parte das obras tratarem dos acontecimentos ocorridos nessa cidade.

Tema 2: Travestis e agentes de segurança pública no pós-ditadura até os dias de hoje

Nesse tema são abordadas as mais variadas práticas policiais de 1985 até os dias de hoje, excluindo-se aquelas que ocorrem no sistema prisional e em sistemas de investigação. Trata-se de um amplo leque de ações e relações que envolvem violências, assassinatos cometidos por policiais, violações de direitos, laços de solidariedade entre policiais e travestis, entre outros.

Na Tabela 7, observa-se que esse é o tema em que a quantidade de obras está mais bem distribuída, sob o aspecto temporal. As primeiras de todo o levantamento aí se encontram, iniciando-se com Mott e Assunção (1987), que trata da prática da automutilação, muito utilizada pelas travestis até o final dos anos 1990, sobretudo como forma de escapar da violência policial. Depois disso, assistimos a um hiato temporal significativo, apenas nove anos depois mais duas obras foram publicadas.

Dos autores que mais produziram, observa-se excessiva fragmentação: apenas três deles escreveram dois textos; os demais, um. 
Quadro 2: Conjuntos de palavras constantes nos títulos do Tema 2

\begin{tabular}{|c|}
\hline $\begin{array}{c}\text { Conflito/s/disputa/contra/enfrentamento/tensões/perseguições (9) } \\
\text { Polícia/policial/militar (6) } \\
\text { Violência/ (6) }\end{array}$ \\
Imprensa/jornalísticas/mídia/páginas (5) \\
Homossexuais/LGBTs (5)
\end{tabular}

De acordo com o Quadro 2, fica patente o teor da maioria dos temas: conflitos, tensões, marcas registradas das relações entre travestis e agentes de segurança pública e a violência vem na esteira dessa realidade. Mais uma vez aparece um conjunto articulado em torno dos meios de comunicação. De fato, parcela considerável dessas obras aborda como a mídia repercute a atuação policial sobre as travestis, aliás, muito do que se sabe provém dessa fonte de informação. Como apontado anteriormente, muito das coberturas desses canais são preconceituosas, transfóbicas e moralistas.

Tema 3: Processos de investigação e apuração de fatos nas instituições de segurança pública

Tema altamente relacionado ao anterior, às vezes misturando-se em um mesmo texto. Se naquele o mote é a atuação de agentes de segurança pública nas ruas e delegacias, neste se trata dos processos de investigação, apuração dos fatos, envolvendo crimes relacionados a LGBT+, sobretudo travestis. Em geral, essa produção destaca a negligência, a morosidade, a falta de vontade de apurar, os pré-julgamentos, os arquivamentos precoces envolvendo esses acontecimentos. Importante registrar, também, a ênfase que se produz, nessas obras, em relação a discursos desses agentes, principalmente delegados e policiais diretamente envolvidos com as ocorrências, veiculados nos mais variados canais da mídia.

Como se observa na Tabela 7, a distribuição temporal dessa produção é irregular. Depois das duas primeiras publicadas em 2006 (CARRARA e VIANNA, 2006; LACERDA, 2006), a retomada acontece em 2010. Se em 2015 não houve produção, a de 2014 destoa dos demais anos.

O autor com maior número de produção é Igor Henrique Lopes de Queiroz, com o total de quatro publicações, seguido por Debora Diniz, Osvaldo Francisco Ribas Lobos Fernandez, Marco Antonio Matos Martins, Érico Silva do Nascimento e Enézio de Deus Silva Jr., com duas publicações cada. 
Quadro 3: Conjuntos de palavras constantes nos títulos do Tema 3

Imagens/imprensa/jornal/notícia/s/páginas/retratos/manchetes (16)

Gays/homossexuais/bissexuais/lésbicas/LGBT/desviantes (9)

Homofobia/homofóbica/homo(trans)fóbica/lesbofobia/transfobia (9)

Violência (8)

Assassina/assassinato/s/mortes/letal (6)

Crimes/vítimas/culpadas/réus/caso (6)

Conflitos/contra (5)

Fonte: Elaboração do autor.

Com relação aos conjuntos de palavras constantes dos títulos, conforme o Quadro 3 acima, mais uma vez - com maior frequência em relação aos demais - observa-se a relevância dos meios de comunicação. De fato, é por meio desse canal que são conhecidas as informações básicas sobre os casos e os processos investigatórios, inclusive os discursos decorrentes. Para que se tenha ideia, de um total de 19 obras, nesse tema, dez se relacionam diretamente à mídia. Os demais conjuntos apresentados são bastante e, obviamente, relacionados ao tema, repercutindo o fato de que, em geral, é o homicídio o centro das atenções. Preocupa a elevada frequência em torno do conjunto homo/transfobia, frequentemente revelando essa característica em relação aos agentes que vão apurar os crimes em questão.

\section{Tema 4: Sistema prisional e encarceramento de travestis}

Trata-se do tema com o maior número de obras (40,90\%), como se pode ver na Tabela 6, e motivo de grande preocupação por parte do movimento LGBT+, pelas brutais condições vivenciadas pelas travestis no sistema carcerário, como apontado na Seção "Breve panorama das relações entre travestis e agentes de segurança pública ao longo do tempo". São obras que expõem as complexidades de um sistema que não foi pensado para trans; muitas dessas abordam casos de presídios que possuem alas apropriadas para LGBT+, apontando as outras tantas dificuldades para as travestis, nessas situações.

A primeira obra sobre o tema, como consta na Tabela 7, data de 2008 (SILVA e PERES, 2008), sendo que o volume da produção se torna substancial a partir de 2012, revelando-se o tema mais produtivo em todos os demais anos seguintes: metade da produção total equivalente a 2012 a 2016 corresponde a essa problemática.

O autor de maior produção não só nesse tema, mas em todo o levantamento é Guilherme Gomes Ferreira, com 11 escritos, correspondendo a um índice de concentração de 24,44\% do 
total. Em seguida vem Adriana Dias Vieira, com cinco, depois, Bruna Andrade Irineu com quatro, Sofia Ciuffoletti com quatro e Mariana Meriqui Rodrigues com três. Os cinco autores respondem por $60 \%$ do total produzido.

O quadro abaixo apresenta as palavras mais frequentes nos títulos das obras ${ }^{24}$.

Quadro 4: Conjuntos de palavras constantes nos títulos do Tema 4

Cárcere/carcere/cárceles/carcerário/clausuras/detenzione/encarceradas/encarceramento/ incarceramento/incarceration/inmates/muralhas/penitenciário/a/presídios/presos/as/prisão/ões /prisional/prisiones/prison/privados/as/espaços (52)

Sofridas/opressão/precárias/segregação/seletividade/sobrevivência/situação/selva/violência/s/ homofobia/vivem/Veronica/Bolina/decência/condições/invisibilidade/experiência/vivências/aco ssado/ambiente/punição (32)

Análise/análisis/analisando/crítica/conhecendo/determinantes/cartografando/ case-study/estudo/notas/considerações/olhar/reflexões/significados (17)

Direito/s/reinvindicações/violações/lei/ perda/perdem-se/acesso (15)

Género/gênero/interseccionalidades/marcadores/interdisciplinar/transfeminista (12)

Fonte: Elaboração do autor.

O primeiro conjunto, articulado em torno da ideia de prisão, encarceramento, é o de maior frequência, como se esperava, na medida que é nisso que o tema se concentra. O segundo é um desdobramento do primeiro e expressa a intenção de abordar e retratar as precárias condições de sobrevivência no sistema carcerário, com vários tipos de opressões; a questão da segregação e seletividade, conforme consta no Quadro 4, é alvo de vários desses estudos. O terceiro, articulado em torno da ideia de análise, de estudo, mostra o assunto como possibilidade de pesquisa, o que costuma ser feito na junção das abordagens relativas ao controle prisional com as questões de gênero, como está expresso no último conjunto de palavras bastante associadas às questões de gênero. O penúltimo se relaciona a outro aspecto patente: as violações de direitos.

\section{Tema 5: Políticas de segurança pública relacionadas às travestis}

A maioria das obras desse tema se relaciona às iniciativas abordadas na Seção "Breve panorama das relações entre travestis e agentes de segurança pública ao longo do tempo" que contemplam a atuação de agentes de segurança pública em relação às travestis, frequentemente na conexão com a legislação, normas institucionais e experiências de treinamento e capacitação. Raramente se encontrou escritos específicos ao universo trans nessa temática que representa $15,45 \%$ do total de obras coletadas, conforme a Tabela 6. Em termos de conteúdos, sobressaem-se as experiências de capacitação, treinamento - em especial, para agentes que estão adentrando as instituições - e 
reciclagem de policiais nas academias de polícias civis, militares e guardas municipais e, em alguns casos, sistema prisional, assim como leis e normas a serem seguidas por esses agentes. Embora haja obras que tratem da situação do país como um todo, inclusive as iniciativas no âmbito do governo federal, chama atenção a quantidade existente sobre experiências regionais e locais: de um total de 17 coletadas, dez referem-se a experiências estaduais e municipais, sobressaindo-se Rio Grande do Sul, seguido por Rio de Janeiro, Minas Gerais e Fortaleza (Ceará).

Como se vê na Tabela 7, as duas primeiras obras desse tema datam de 2006 (SILVA, 2006a, 2006b), mantendo-se uma distribuição regular ao longo dos anos subsequentes. A autora que mais produziu, totalizando cinco publicações, com índice de concentração de 29,41\%, é Rosimeri Aquino da Silva, educadora que retrata sua larga experiência com alunos em academias de polícia no Rio Grande do Sul. Em seguida, vêm Rezende Bruno de Avelar, Nicole Gonçalves da Costa, Cleyton Feitosa Pereira, Silvia Ramos e Gustavo Gomes da Costa Santos, com duas publicações cada.

Quanto às palavras frequentes nos títulos das obras, o resultado é apresentado no quadro abaixo.

Quadro 5: Conjuntos de palavras constantes nos títulos do Tema 5

GLBT/LGBT/lésbicas/bissexuais/gays/homossexuais/mulheres/minorias/diversidade/ identidades/heterogêneas (23)

Política/s/agenda/implementação/institucionais/promoção/desafios/realização/ respostas (16) Aula/educação/estudo/formação/práticas/professores/saberes/sala (11)

Segurança (10)

Pública/s/público (9)

Desvio/estigmatização/discriminação/homofobia (6)

Fonte: Elaboração do autor.

A frequência dos termos expressa a concentração de obras baseadas em dois tipos de iniciativas: as experiências educacionais e de formação em instituições de segurança pública e os planos, programas, criação de órgãos, geralmente no âmbito do Governo Federal.

\section{Considerações finais}

Os conteúdos da grande maioria das obras deste levantamento expressam a crítica contra o discurso heteronormativo e transfóbico entranhados na sociedade brasileira, o que afeta profundamente as travestis, denunciando as opressões, violências e violações que sofrem, nesse caso, na área da segurança pública e, mormente, vindo de seus agentes, na esteira de teorias, abordagens e conceitos que os suportam. Sob esse ponto de vista, essa produção é um bloco 
relativamente homogêneo e pode ser vista como matriz discursiva que se junta àquela que vem dos movimentos, organizações, núcleos e grupos de pesquisa relacionados à pauta LGBT+e talvez tenha influenciado para avanços na legislação e nas políticas públicas, mas não sendo capaz de eliminar tudo aquilo por que ainda passam as travestis brasileiras nessa área em especial, chamando atenção, inclusive, o elevado número de assassinatos de travestis que, nos últimos tempos, não sofre mudanças substanciais ${ }^{25}$. É sobre essa produção que se buscou aqui esmiuçar um pouco mais, sob o ângulo da bibliometria.

Ao observar a evolução temporal dessa produção, percebe-se o crescimento recente, basicamente nesta década, expresso na preocupação acadêmica com a temática travestis e segurança pública, concentrada nas regiões Sul e Sudeste do país, bem posterior a outros temas que já vinham ocupando espaço de forma significativa, tais como: saúde, educação e as questões de gênero relacionadas à travestilidade ${ }^{26}$. Também, ressalta-se o baixo número, perante a produção total, de livros, teses e dissertações. De qualquer forma, sob diferentes pontos de vista e interesses, a temática da travestilidade está muito presente na sociedade, o que deverá impulsionar, ainda mais, a produção acadêmica, respingando também naquelas relativas à segurança pública em um processo de engrossamento ao aumento que já vem ocorrendo.

Quanto à temática dessa produção há certo equilíbrio, com exceção da supremacia (mais de $40,90 \%$ do total) das obras relacionadas ao sistema carcerário (Tema 4), com destaque significativo para um pequeno número de autores que, isoladamente, contribuem significativamente para a produção total, fenômeno frequente no meio acadêmico. Se pegarmos arbitrariamente o total de obras referentes a autores que produziram no mínimo quatro, o índice de concentração é de 34,5\%.

\section{Notas}

\footnotetext{
1 Entende-se por bibliometria a "análise estatística dos processos de comunicação escrita, tratamento quantitativo (matemático e estatístico) das propriedades e do comportamento da informação registrada" (FIGUEIREDO, 1977 apud LIMA, 1986, p. 127).

2 Torna-se cada vez mais frequente pessoas que antes se identificavam como travestis passarem a se dizer mulheres transexuais ou apenas trans e, às vezes, simplesmente mulheres, independentemente da realização da operação de redesignação sexual. Como afirma Brum (2014, p. 48): “É possível que a transexual de hoje, seja a travesti de ontem e o contrário também pode ser verdadeiro. Entendemos, a partir disso, que as relações que constituem as travestis e transexuais funcionam sem a pretensão de encaixarem-se numa norma, elas fluem, flexibilizam, transgridem".

${ }^{3}$ A utilização do artigo masculino "o" para referir às travestis ainda era comum à época. Com o tempo, em respeito à sua feminilidade e às lutas identitárias, passou-se a utilizar o artigo feminino "a".

${ }^{4} \mathrm{O}$ total de registros não coincide com o total das obras coletadas porque mais de um termo pode fazer parte de um mesmo título, assim como há títulos sem o registro das palavras selecionadas.

5 "Desde meados da década de 70, a cidade de São Paulo transformou-se em corpo esquadrinhado, vigiado, controlado e reprimido por inúmeras práticas policiais" (FERNANDES, 1989, p. 123).

${ }^{6}$ Por outro lado, na época, setores da sociedade se colocaram veementemente por meio de movimentos, passeatas, artigos etc. contra essa orientação, no rastro da cruzada movida pelo jornal, oponente ao Estadão, a Folha de S. Paulo. De
} 
qualquer forma, o clamor e apoio de jornais e articulistas, pretensamente representantes de parcela da sociedade, na "caça" às travestis será uma marca registrada até os dias de hoje, sobretudo em cidades de pequeno porte.

${ }^{7}$ Ver Green (2000) e Trevisan (2007).

${ }^{8}$ Em São Paulo, em 1987, logo após a abertura, tivemos a Operação Tarântula, promovida pela Polícia Civil, por iniciativa da Prefeitura, com claras intenções higienistas. Dessa vez, o argumento era o perigo e o estigma de contágio da Aids. Apesar da operação ter sido suspensa logo depois de seu início, desencadeou-se uma onda de assassinatos de travestis. Embora se acredite que a autoria partisse de um suposto grupo anti-gay, havia suspeita da participação de policiais em algumas delas, embora isso não tenha sido comprovado e nem investigado. Naquele período, também, as travestis reclamavam da violência dos guardas municipais. Esses fatos levaram à realização do documentário Temporada de caça, dirigido por Rita Moreira (1988), com ênfase ao apoio de parcela da população à morte das travestis.

${ }^{9}$ Famosos foram os casos do jornalista José Augusto Berbert, de $A$ Tarde, em Salvador, e do radialista Afanásio Jazadji, da Rádio Globo e Capital, com posições e discursos assumidamente transfóbicos.

${ }^{10}$ Atualização e revisão do tratamento acadêmico dado ao tema é realizado por Ferreira (2018).

${ }^{11}$ No caso de capítulos, o material foi desprezado.

${ }^{12}$ Nesse caso, quando a abordagem é marginal ou superficial, desprezei. Assim, Kulick (2008), Silva (1993), Trevisan (2007) e Albuquerque e Janelli (1995), para ficar em exemplos notáveis, não foram consideradas no levantamento. Embora haja menções à atuação de agentes de segurança pública, principalmente policiais, essa não é a razão de ser das obras. $\mathrm{O}$ assunto aparece de forma esparsa.

${ }^{13}$ Por capítulos, estou me referindo aos livros de organização, isto é que contêm artigos de vários autores.

${ }^{14}$ Por exemplo, um artigo publicado nos anais de um congresso e posteriormente em um periódico e/ou como capítulo de livro, ou uma tese publicada na forma de livro.

${ }^{15}$ Seguramente, o total de 110 obras integralmente relativas ao assunto em pauta é número ínfimo dentre toda a produção sobre travestilidades, sobretudo se compararmos com aquela que se relaciona com saúde e educação. A ausência de alguns anos indica que não houve produção.

${ }^{16}$ Por exemplo, se em 2014 a produção total foi de 30, no ano seguinte caiu para metade, aumentando novamente em 2016, mas ficando aquém daquele.

17 Universidade Católica de Salvador.

${ }^{18} \mathrm{O}$ mais adequado seria o enquadramento de toda a produção nesse critério (por áreas) e não apenas teses e dissertações. Essa possibilidade é inviabilizada pelo fato de que para boa parte das obras não consta essa informação, nem nas próprias e muito menos na Plataforma Lattes, o que me obrigaria a realizar um enquadramento pessoal, o que não é recomendável.

${ }^{19} \mathrm{O}$ enquadramento realizado é de minha inteira responsabilidade e se baseou na centralidade do tema na obra, o que requereu bastante atenção uma vez que uma mesma produção pode apresentar elementos de mais de um tema.

20 Disponibilizarei, para quem tiver interesse, uma lista com as obras coletadas, divididas por temas e em ordem cronológica. Basta me contatar por e-mail. Embora a análise bibliométrica deste artigo vá até 2016, informo que venho coletando as obras enquadradas até os dias de hoje.

${ }^{21}$ Ver Ocanha (2014).

${ }^{22} \mathrm{Em}$ todos os quadros desse tipo, aqui apresentados, desconsiderei as palavras travesti/s, transexual/is, dado que previsivelmente elas estão presentes na maioria das obras.

${ }^{23}$ Estou ciente de que o título de uma obra nem sempre expressa o teor desta, embora possa nos dar uma ideia a esse respeito. $O$ ideal seria utilizar as palavras-chave, porém esse recurso está ausente em alguns tipos de escritos (livros, capítulos de livros e parte dos artigos publicados em anais).

${ }^{24}$ Em função do maior número de obras nesse tema, utilizei um limite (corte) maior: dez palavras.

${ }^{25}$ Supreendentemente, o número de travestis assassinadas contabilizadas vem se elevando. Por exemplo, partindo de um número de 68 homicídios, em 2009, em quase todos os anos houve elevação desses totais. Quando houve queda, esta foi pequena. Chegou-se a 134 em 2014, 144 em 2016 e 179 em 2017 (ANTRA, 2018).

${ }^{26}$ Silvia Ramos afirma, relembrando o final da década dos 1990, que "é notável o contraste entre a postura predominantemente passiva no campo de propostas para a segurança pública e justiça e o vigor dos discursos, demandas e práticas que o ativismo homossexual produziu na área da saúde" (RAMOS, 2010, pp. 132-133). 


\section{Referências}

ALBUQUeRQUE, Fernanda Farias de; JANELLI, Maurizio. A princesa: A história do travesti brasileiro na Europa escrita por um dos líderes da Brigada Vermelha. Rio de Janeiro: Nova Fronteira, 1995.

ANTRA. Mapa dos assassinatos de travestis e transexuais no Brasil em 2017. Brasília: Associação Nacional de Travestis e Transexuais (Antra), 2018.

BRASIL. I Programa Nacional de Direitos Humanos. Brasília: Ministério da Justiça, 1996.

BRASIL. II Programa Nacional de Direitos Humanos. Brasília: Ministério da Justiça, 2002.

BRASIL. III Programa Nacional de Direitos Humanos. Brasília: Ministério da Justiça, 2009a.

BRASIL. Relatório final da 1a Conferência Nacional de Segurança Pública. Brasília: Ministério da Justiça, 2009b.

BRUM, Indira Saad. Da nomeação às práticas de prostituição: Um olhar sobre travestis e transexuais a partir de artigos científicos encontrados na SciELO. Dissertação (Mestrado em Educação) - Universidade Federal do Rio Grande, Rio Grande, 2014.

BUTLER, Judith. Problemas de gênero: Feminismo e subversão da identidade. Rio de Janeiro: Civilização Brasileira, 2003.

CARDOZO, Fernanda. Das dimensões da coragem: Socialidades, conflitos e moralidades entre travestis em uma cidade no sul do Brasil. Dissertação (Mestrado em Antropologia Social) Universidade Federal de Santa Catarina, Florianópolis, 2009.

CARRARA, Sérgio; VIANNA, Adriana. “'Tá lá um corpo estendido no chão...': A violência letal contra travestis no município do Rio de Janeiro". Physis: Revista de Saúde Coletiva, vol. 16, n. 2, pp. 233-249, 2006.

CNDC. Brasil sem homofobia: Programa de combate à violência e à discriminação contra GLBT e de promoção à cidadania homossexual. Brasília: Conselho Nacional de Combate à Discriminação (CNDC), Ministério da Saúde, 2004.

DINIZ, Debora; OLIVEIRA, Rosana Medeiros de (orgs). Notícias de homofobia no Brasil. Brasília: LetrasLivres, 2014.

FERNANDES, Heloisa Rodrigues. "Rondas à cidade: Uma coreografia do poder". Tempo Social, vol.1, n. 2, pp. 121-134, 1989.

FERREIRA, Guilherme Gomes. Donas de rua, vidas lixadas: Interseccionalidades e marcadores sociais nas experiências de travestis com o crime e o castigo. Tese (Doutorado em Serviço Social) - Instituto Universitário de Lisboa, Lisboa, 2018.

GARCIA, Marcos Roberto Vieira. Dragões: Gênero, corpo, trabalho e violência na formação da identidade entre travestis de baixa renda. Tese (Doutorado em Psicologia) - Universidade de São Paulo, São Paulo, 2007. 
GREEN, James. Além do carnaval: A homossexualidade masculina no Brasil do século XX. São Paulo: Unesp, 2000.

KULICK, Don. Travesti: Prostituição, sexo, gênero e cultura no Brasil. Rio de Janeiro: Fiocruz, 2008.

LACERDA, Paula Mendes. O drama encenado: Assassinatos de gays e travestis na imprensa carioca. Dissertação (Mestrado em Saúde Coletiva) - Universidade Estadual do Rio de Janeiro, Rio de Janeiro, 2006.

LEITE JR., Jorge. "Nossos corpos também mudam": Sexo, gênero e a invenção das categorias "travesti" e "transexual" no discurso científico. Tese (Doutorado em Ciências Sociais) Pontifícia Universidade Católica de São Paulo, São Paulo, 2008.

LIMA, Regina Célia Montenegro de. "Bibliometria: Análise quantitativa da literatura como instrumento de administração em sistemas de informação". Ciência da Informação, vol. 15, n. 2, pp. 127-133, 1986.

LUCON, Neto. "'Destruir, e não me inserir', diz profissional do sexo Indianara Siqueira sobre sociedade". Blog do Neto Lucon, 12 fev. 2016. Disponível em: https://nlucon.com/2016/02/12/destruir-e-nao-me-inserir-diz-profissional-do-sexoindianara-siqueira-sobre-sociedade/MARTINS, Humberto Vieira. "O que se conta e como se conta: Um pouco da história do DDH”. Comunicações do Iser, vol. 56, n. 1, pp. 40-52, 2001.

MELLO, Luiz; BRITO, Walderes; MAROJA, Daniel. "Políticas públicas para a população LGBT no Brasil: Notas sobre alcances e possibilidades”. Cadernos Pagu, n. 39, pp. 403-429, 2012.

MELLO, Luiz; AVELAR, Rezende Bruno de; BRITO, Walderes. "Políticas públicas de segurança para a população LGBT no Brasil”. Revista Estudos Feministas, vol. 22, n. 1, pp. 297-320, 2014.

MOTT, Luiz; ASSUNÇÃO, Aroldo. “Gilete na carne: Etnografia das automutilações dos travestis da Bahia”. Temas Imesc - Sociedade, Direito, Saúde, vol. 4, n. 1, pp. 41-56, 1987.

NATIVIDADE, Marcelo Tavares. "Políticas de segurança pública e a promoção de práticas de respeito à diversidade sexual e diversidade de gênero no Ceará e no Rio de Janeiro: novos conflitos sociais no espaço público". Anais do Encontro Anual da Anpocs, vol. 37. Caxambu: Anpocs, 2013.

OCANHA, Rafael Freitas. “Amor, feijão, abaixo camburão”: Imprensa, violência e trottoir em São Paulo (1979-1983). Dissertação (Mestrado em História) - Pontifícia Universidade Católica de São Paulo, São Paulo, 2014.

RAMOS, Silvia. "Disque defesa homossexual: Narrativas da violência na primeira pessoa". Comunicações do Iser, vol. 56, n. 1, pp. 53-66, 2001.

RAMOS, Silvia. "Respostas do movimento LGBT à homofobia e a agenda da segurança pública". In: POCAHY, Fernando (org). Políticas de enfrentamento ao heterossexismo: Corpo e prazer. Porto Alegre: Nuances, 2010, pp. 125-142.

ROLIM, Marcio. "Presos homossexuais são tratados com exorcismo em presídio de Mato Grosso". Hornet, 7 ago. 2018. Disponível em: https://hornet.com/stories/pt-pt/presos-homossexuais/

SÁ, Priscilla Placha. Dossiê: As mulheres e o sistema penal. Curitiba: OABPR, 2015. 
SILVA, Cláudio Nascimento. Diretrizes para o Plano Nacional de Segurança Pública para o Enfrentamento da Homofobia: Relatório resumido de propostas do I Seminário Nacional de Segurança Pública e Combate à Homofobia. Rio de Janeiro: Grupo Arco-Î́ris de Conscientização Homossexual e Movimento D’Ellas, 2007.

SILVA, Flavia; PERES, Wiliam. Travestis, clausuras e devires: cartografando os espaços marginais do desejo. $7^{\circ}$ Congreso de Salud Mental y Derechos Humanos. Buenos Aires: Memorias de El $7^{\circ}$ Congreso de Salud Mental y Derechos Humanos 2008.

SILVA, Hélio. Travesti: A invenção do feminino. Rio de Janeiro: Relume-Dumará, 1993.

SILVA, Rosemeri Aquino da. Identidades heterogêneas na contemporaneidade violenta: Um estudo a partir de uma sala de aula singular. Tese (Doutorado em Educação) - Universidade Federal do Rio Grande do Sul, Porto Alegre, 2006a.

SILVA, Rosemeri Aquino da. "Nós lidamos com os restos da sociedade’: Mulheres, homossexuais, travestis - Corpos sob controle e sob saberes institucionais". Anais do Seminário Internacional Fazendo Gênero 7: Gênero e preconceitos. Florianópolis: Mulheres, 2006b.

SOUZA, Camila Cristina de Castro. "Política públicas para população LGBT no Brasil: Do estado de coisas ao problema político”. VII Jornada Internacional Políticas Públicas. São Luís: Universidade Federal do Maranhão, 2015.

TEMPORADA de caça. Produção de Rita Moreira. São Paulo: Rita Moreira Produções, 1988.

TREVISAN, João Silvério. Devassos no paraíso: A homossexualidade no Brasil, da colônia à atualidade. Rio de Janeiro: Record, 2007.

\begin{abstract}
CASSIANO RICARDO MARTINES BOVO (cassiano.bovo@gmail.com) é assessor científico do Fundo Mackenzie de Pesquisa (Mackpesquisa, São Paulo, Brasil). Tem doutorado pelo Programa de Estudos Pós-Graduados em Ciências Sociais da Pontifícia Universidade Católica de São Paulo (PUC-SP, São Paulo, Brasil), mestrado pelo Programa de Estudos Pós-Graduados em Economia Política da PUC-SP e graduação em economia pela mesma universidade.
\end{abstract}

https://orcid.org/0000-0002-9471-5597 